\title{
O ensino de produção textual com foco no processo: a versão textual da ação retórica
}

\section{Ricardo Ugeda Mesquita ${ }^{1}$ Rosíris Flocco ${ }^{2}$}

$\mathrm{O}$ trabalho com as palavras é sempre um desafio. Apesar de encantadoras, as palavras são, também, perturbadoras por trazerem em si um caráter polissêmico e dependerem de um usuário competente e de um intérprete não menos eficaz. As palavras mais simples vêm carregadas de posicionamentos, sentimentos, visões de mundo e opiniões. Assim, na escrita, estamos muito ligados às nossas palavras pelo impulso de comunicar e transmitir as significações que brotam de nós mesmos a fim de alcançar o outro, nosso auditório. Quem fala quer persuadir, ainda que diga que não. Quem escreve quer persuadir, também, por meio de seu texto.

Diante disso, a retórica impõe-se como a arte de persuadir um auditório. O discurso oratório é essencialmente dialético e persuasivo. Por conseguinte, a retórica alia-se com a produção escrita e tem a dialética como elemento componente. Afinal, como afirma Tringali (2014, p. 22): “Tudo que é discutível é dialético". Assim, a persuasão e a dialética são partes integrantes do processo de escrita.

A escrita apresenta um discurso que supõe, como todo discurso, um outro, anterior, com seus valores, opiniões e sentimentos. O "novo" discurso,

\footnotetext{
1 Mestrando pela PUC-SP; Bacharel em Direito pela Mackenzie/SP; Licenciado em Letras (Português/Inglês) e Pedagogia, com extensão em Supervisão Escolar (UnG); Membro do Grupo ERA; Bolsista CAPES.

2 Mestranda em Língua Portuguesa pela PUC-SP; Especialista em Língua Portuguesa pela PUC-SP; Membro do Grupo ERA; Bolsista CAPES.
} 
materializado pela escrita, corresponde a um outro discurso para negá-lo ou afirmá-lo, e essa propriedade decorre da natureza dialética do texto retórico. O texto, na escola ou no mundo, dialoga (ou deveria dialogar) com outro discurso posto ou contraposto. Essa característica contribui para dar o tom de realismo ao ato de escrever: há sempre um auditório delineado no momento da produção.

Como bem lembra Bazerman (2015), no percurso da escrita - a versão textual da ação retórica - deve-se enfocar a identificação e a cristalização do espaço comunicativo. Apesar de o produto final da escrita ser externo ao escritor - por depender do outro polo da relação comunicativa permeado pelo texto - a maior parte do trabalho e da significação que faz o texto realizar-se plenamente e atingir sua eficácia comunicativa advém do trabalho do escritor.

Em meio a esse trabalho, o escritor não só tem o direito à palavra, mas, sobretudo, o direito de tomá-la com liberdade, franqueza e destemor. Essa é uma grande descoberta grega, a parrésia, como ensina Tringali (2014).

O princípio de adequação determina a funcionalidade de tudo no discurso. Os gregos chamavam esse princípio de prépon $=$ o que convém e kairós = no momento oportuno. Os latinos diziam: decorum, convenientiaque traduzimos como decoro e conveniência. (TRINGALI, 2014, p. 33).

Diante desse panorama, levantamos questionamentos relativos às práticas de ensino de produção textual, no ambiente escolar, à luz da sociorretórica, cujo arcabouço teórico ressalta a importância dos gêneros também na escrita, pois por meio de um gênero, como explica Miller (1984), é possível entender melhor as situações em que nos encontramos e as possibilidades de fracasso ou sucesso ao agirmos juntos. $O$ gênero, recorrentemente, engloba um aspecto da racionalidade cultural e serve tanto como um índice de padrões culturais quanto como ferramenta exploratória das realizações de alguns falantes ou escritores em particular; para o estudante, por sua vez, ainda de acordo com Miller (1984), os gêneros servem como chaves para a compreensão de como participar das ações de uma determinada comunidade. Assim, a sociorretórica funda-se em princípios práticos e reflexivos do enunciado estratégico em contexto, do ponto de vista dos participantes do processo comunicativo, o que se apresenta extremamente salutar no contexto da produção textual escolar.

É comum, entre os teóricos da linguagem, a crítica ao ensino de pro52 dução textual nas escolas brasileiras. Apontam-se como problemas gerais 
dessa atividade de escrita a pouca utilidade social dos textos produzidos pelos alunos, a insistência de muitos professores em apenas considerar o resultado final, ou produto, da escrita do aluno, o predomínio do ensino de regras gramaticais descontextualizadas, entre outras perspectivas críticas sempre consideradas como "problemas". Por isso, propomo-nos, neste capítulo, a pensar o ensino de produção textual com foco retórico no processo da escrita, no fazer que pressupõe uma relação do produtor do texto com o seu possível leitor.

\section{A produção textual escolar: do produto ao processo}

Normalmente, nas redações escolares, o texto é dirigido a apenas um auditório, o professor. Isso faz com que o aluno (que deveria ser um autor) amplie cada vez mais a superficialidade em seu texto e afaste-se cada vez mais da autenticidade de sua produção. No entanto, a partir das lições de retórica, somos impelidos a pensar o conceito de auditório, imprescindível para a existência do diálogo (orador - auditório) e, por isso, o orador (autor do texto) deve estar atento, segundo explica Tringali (2014):

a) à reação do auditório;

b) ao objetivo do auditório; e

c) ao tempo em que a questão é tratada pelo auditório e ao valor a ela atribuído.

Para fins retóricos, o auditório é muitíssimo importante. Logo, é importante identificá-lo e conhecê-lo, o quanto possível. Um discurso retórico, como ensina Ferreira (2015) não pode prescindir de um auditório. Em nosso caso, o auditório pode ser representado pelo leitor do texto. "É o auditório que, como leitor ou ouvinte de um ato retórico, concentra toda a atividade do orador", conforme Ferreira (2015, p. 21).

A partir dessa ideia, busca-se, durante o processo de escrita, suscitar no aluno um olhar para o modo de funcionamento real da argumentatividade implícita em seu texto, ou seja, a relação dialética presente na produção textual. Busca-se, ademais, orientar seu olhar para o auditório (o leitor) a que se dirige. Poderíamos pensar que nem todo discurso é argumentativo, que nem todo texto a ser solicitado como proposta ao aluno é argumentativo - se pensarmos na argumentação em sentido estrito -, porém, na verdade, a atitude dialética presente no processo criador do texto é uma relação de 
sentido que se estabelece entre enunciados na comunicação verbal. Todo texto é dotado de argumentatividade, independentemente do gênero, e o orador é certamente a causa eficiente do discurso.

Nesse sentido, Geraldi (1998) adverte que, ao produzir seu texto, o aluno deve ser considerado como sujeito produtor, a fim de que possa ampliar habilidades de escrita, porque será interpretado e avaliado não só pelo professor, mas, também, por diversos leitores. Isso seria o ideal, mas a prática demonstra que nem sempre é assim. Nessa perspectiva do processo de construção da escrita, Antunes (2003), em sintonia com Geraldi (1998), evidencia que um dos maiores problemas do ensino de produção textual é que o aluno possui uma escrita mecânica e artificial, visando a simplesmente cumprir tarefas propostas. Além disso, os docentes das escolas brasileiras mostram-se muito mais preocupados com o momento da correção e da avaliação do que como percurso. Por conta disso, a redação na escola ainda é um discurso dirigido a um auditório particular (o professor) e tal fato amplia a artificialidade e afasta a autoria do aluno que escreve.

A simples correção gramatical e devolução do texto ao aluno não propicia um momento de reflexão sobre a própria produção. Por isso, no que se refere ao auxílio na prática da produção textual, Geraldi (1998) considera viável que o professor verifique as maiores incidências nas produções textuais de seus alunos e, mediante a constatação, conduza o autor (aluno) para os ajustes necessários em seu texto. Ao fazê-lo, o foco do ensino de produção textual desloca-se do produto (a redação pronta) para o processo (etapas de produção textual).

Ainda nesse diapasão, outro aspecto a ser considerado é a visão do aluno com relação à correção textual. Se o aluno considerar o ato do professor como um exercício interpretativo em vez da correção formal, irá tornar-se mais próximo daquilo que representa ser autor e não mero reprodutor ou produtor de texto. $\mathrm{O}$ autor reflete e admite as teses do auditório e repensa tais teses para assegurar o melhor dizer para um determinado argumento, assunto ou tema. O aluno, se inserido nessa nova perspectiva, pode compreender que escrever não é apenas uma atividade voltada para transcrever normas e regras gramaticais para um único auditório (professor), mas para diversos tipos de leitores, inclusive o professor, interpretarem o seu texto.

No contexto escolar, interpretar constitui sempre uma inferência ou conclusão autorizada por sinais, indícios ou indicadores presentes em um texto, como explica Macedo (2002). Interpretar pressupõe, outrossim, acrescentar sentido, ler nas entrelinhas, preencher os vazios e, dentro dos 54 limites possíveis do texto, ampliar o conteúdo. Tal ampliação pode ser 
um pouco daquilo que o professor pode realizar ao corrigir o texto de um aluno. Podemos dizer, inclusive, que esse ato interpretativo está contido na correção. Apesar de curioso, esse novo olhar pode cooperar para que o professore o aluno entendam a correção como uma atividade de interpretação e não como um mero "caça-erros".

Outra medida que contribui com a interação entre professor e aluno, proposta por Passarelli (2012), é a escolha de uma produção para se realizar um ajuste coletivo. Tal exercício ativa os momentos retóricos clássicos, ainda que o aluno não conheça cada um deles. Os aspectos retóricos envolvidos na produção com ajuste coletivo são esquematizados por Barthes (1975):

\begin{tabular}{|lll|}
\hline Inventio & héuresis invenire quid dicas & (= encontrar o que dizer) \\
Dispositio & táxis inventa disponere & (= dispor o que for encontrado) \\
Elocutio & léxis ornare verbis & (= ornar com palavras) \\
Actio & hypócris agere et pronuntiare & (= atuar e enunciar) \\
Memoria & mnéme memoriae mandare & (= confiar à memória) \\
& & \\
\end{tabular}

Fonte: Barthes (1975, p. 182)

Se escrever, de fato, é uma atividade de interação social e de ação contextualizada, precisamos garantir que haja uma saudável intervenção de todos nesse processo. Certamente, os ajustes não serão apenas no plano formal, mas, também, no plano do conteúdo, uma vez que os colegas, na condição de leitores, produzem sentidos tanto locais como gerais no texto. O professor, por sua vez, auxilia o aluno que produziu o texto com sugestões e explicações sobre fatos da língua e adequações discursivas. Essa atividade contribui consideravelmente para a inventio e a dispositio nos próximos trabalhos, uma vez que tais momentos retóricos são diretamente acionados, ainda que sem a consciência dos alunos.

Ao considerar esses aspectos retóricos, os professores são convidados a repensarem suas práticas pedagógicas e orientarem os alunos a ressignificarem seu texto, com o intuito de torná-lo gradativamente mais coerente e coeso. O papel do professor, como parece ser consenso, é o de atuar como um mediador da aprendizagem e participar do processo de construção. O problema é que, ao auxiliar os alunos, muitos professores costumam priorizar apenas a construção de textos de maneira mecânica. Nessas produções textuais, os estudantes prendem-se às normas gramaticais e 
ortográficas e limitam-se a produzir textos apenas para atingir uma nota suficiente para sua aprovação.

Diante disso, Cavalcante (2014) afirma que o texto só existe se tiver coerência comunicativa, não exclusivamente linguística e gramatical, uma vez que depende da participação de um interlocutor no processo da escrita. Um texto composto apenas pela superficialidade textual é um material linguístico que necessita ser moldado até que atinja a sua completude.

Para auxiliar o aluno no desenvolvimento da competência escritora, Passarelli (2012) propõe aos docentes formas de ensinar a produção de textos por meio de etapas que enfatizam o processo de construção do texto. A seguir, abordaremos um pouco dessas etapas, jungidas aos princípios que compõem o sistema retórico.

\section{A construção textual passo a passo: uma proposta desafiadora}

Inserir-se num episódio de escrita cria desafios, que podemos preferir não ter. Primeiramente, um episódio de escrita solicita um trabalho cognitivo, em geral, bastante árduo, que pode de acordo com Bazerman (2015, p. 184), "dar dores de cabeça", mas também prazeres finais de realização e descoberta. Em segundo lugar, esse trabalho exige um compromisso que impõe uma obrigação. Nem sempre nós, professores, ou nossos alunos estamos dispostos a isso. Em terceiro lugar, a escrita estabelece uma relação com os outros, representada no texto ou a quem o texto é dirigido. Assim, atuar em uma situação de produção de texto representa um risco real de fracasso ou sucesso.

Diante de tal constatação, como já explicitamos anteriormente, a escrita deve ser considerada como processo. Portanto, destaca-se a importância de levar o discente a seguir etapas: planejar, escrever, revisar ou reescrever e editar. Cada um desses momentos precisa ser monitorado, na escola, pelo professor e, também, pelo próprio aluno, que deve ser, gradativamente, munido de estratégias para automonitorar-se.

Antes de mais nada, o primeiro passo nessa proposta é motivar o aluno para a atividade a ser desenvolvida. É hora de ativar conhecimentos prévios, levantar hipóteses, instigar a ação. É o momento de contextualizar a atividade e certificar-se de que o estudante já tem uma percepção da situação, pois, conforme lembra Bazerman (2015), o impulso de escre- 
ver baseia-se em um tipo de orientação psicológica para a ação. O autor esclarece que esse impulso é chamado pelos psicólogos de excitação. Nesse sentido, declara:

\begin{abstract}
Algo chama nossa atenção como precisando potencialmente de alguma atitude, então reagimos, colhemos informações e começamos a pesar opções de ação, de forma consciente ou não. É importante perceber o reconhecimento desse estado de atenção especificamente dirigido à ação, para não negá-lo ou combatê-lo, mas aproveitá-lo ao máximo. (BAZERMAN, 2015, p. 180).
\end{abstract}

Uma vez motivado, o aluno deve ser orientado para o planejamento da escrita. Ao contrário do que muitos pensam, o planejamento é uma forma de ganhar tempo. Assim, o aluno é levado a pensar o quê e para quem irá escrever, de forma a conseguir criar um modelo mental de suas primeiras ideias. Nessa primeira etapa, não há necessidade de uma confecção escrita. Essa etapa é chamada, no contexto retórico, de inventio ${ }^{3}$, fase que se ocupa de encontrar o que dizer, ou no texto escrito, buscar-se o que escrever. Nesse momento, levanta-se um estoque de material. É o momento de seleção e não necessariamente de invenção das provas, argumentos que embasarão o discurso. É a retórica do conteúdo chamada ao plano de ação do escritor.

$\mathrm{Na}$ etapa do planejamento do texto, devem ser dadas ao aluno as orientações sobre vários dos aspectos que envolvem a produção do texto: qual é o gênero a ser desenvolvido e seus elementos constitutivos principais; qual o perfil do público a que se destina o texto - o foco no auditório; em que suporte e veículo o texto será divulgado; qual a variedade ou o registro linguístico mais adequado à situação; dentre outros detalhes da proposta.

$\mathrm{Na}$ sequência, ou seja, na segunda etapa, é o momento de passar para o papel e traduzir em palavras o que se pretende comunicar. É hora de transcrever as primeiras ideias sobre o que fora planejado mentalmente

3 A retórica se divide, de acordo com Tringali (2014), em cinco partes, a saber: a invenção, a disposição, a elocução, a memória e a ação. A partir de uma apresentação bastante difundida, a retórica - aqui entendida como ciência do discurso voltada para a argumentação - preconiza que para se fazer um discurso é preciso cumprir etapas: encontrar o que dizer (invenção), organizar o encontrado (disposição), colocá-lo em palavras (elocução), memorizar as palavras (memória) e, por fim, proferir o discurso (ação). 
para que o texto comece a tomar forma provisória e o aluno esboce um rascunho. Segundo as lições da retórica, estamos diante da fase da dispositio, que almeja organizar o encontrado e planejar a maneira de dispor as diferentes partes do texto. Nessa etapa, é importante identificar e observar os principais elementos que deverão compor cada uma das partes do texto - do exórdio à peroração.

A seguir, é hora de colocar em palavras, fase na retórica chamada de elocutio (elocução). O aluno, nessa etapa, passa a ter maior atenção na forma de apresentar o seu texto com clareza, concisão, adequação e elegância. Nesse momento, o professor pode solicitar aos alunos que troquem os textos e leiam em voz alta, pois na interação o processo enriquecer-se-á muito mais.

De posse da primeira versão ou texto provisório, o aluno entra na terceira etapa. Trata-se de fazer uma revisão e posterior reescrita de seu texto. É nessa fase que o escritor pode dialogar com seu próprio texto. Muitas vezes, o professor ou o outro colega que leu a primeira versão percebe pontos que podem ser aprimorados pelo aluno produtor e auxiliar no processo de revisão.

Essa é a oportunidade, segundo Passarelli (2012), de recriar sentenças, amarrar as ideias, refazer trechos, entre outras ações. O aluno é o próprio revisor de seu texto e atua como uma espécie de "guardião". Essa prática de correção de texto não é realizada só pelo professor, mas, também, como destacado acima, por um colega e possui uma significativa contribuição no processo da composição da escrita.

Chega-se, então, à quarta etapa, o momento da editoração, da diagramação visual, do processo de acabamento do texto. Nessa etapa, o professor pode orientar o aluno para as possíveis mudanças e ajustes finais com as modificações que julgar necessárias, no intuito de levar o aluno a adquirir domínio pleno da modalidade discursiva da qual participa e do gênero em que se insere sua produção. Essa abordagem é responsável pela construção de um ambiente efetivo de criação.

As produções realizadas nesse espaço criador e resultante de propostas relevantes devem, sempre que possível, ser expostas ao público, pois assim os alunos podem avaliar seu percurso criador: por exemplo, podem rever suas produções de um ano para o outro; de uma proposta para a outra; podem incorporar, por conseguinte, com mais facilidade, as observações do professor sobre suas dificuldades, de maneira a tornarem-se naturalmente mais críticos em relação ao próprio texto e ao de seus colegas. 
O interessante de práticas dessa natureza é que os alunos:

- produzem textos para um determinado público, estabelecido previamente. Há, portanto, um leitor/interlocutor/auditório real, que exige um texto coerente, coeso e interessante;

- passam a ter maior consciência da necessidade de revisar com cuidado seu texto; afinal, têm em vista um leitor/interlocutor/ auditório real, além de seu professor;

- são envolvidos em diferentes práticas, individuais e coletivas, que vão desde o contato, o estudo e a produção de textos de diferentes gêneros até práticas secundárias, mas não menos importantes, como tomada de notas, distribuição de tarefas, interação com pessoas de dentro ou de fora da escola;

- sentem necessidade de ler muitos outros textos, do mesmo gênero ou de outros com a mesma temática, para produzirem o seu, para saberem como se organizam, quais são as suas características e seus elementos constitutivos;

- ampliam seu universo cultural, à medida que precisam do envolvimento de várias áreas com seus saberes.

\section{Considerações finais}

Diante do exposto, entendemos que o ensino de produção textual, embora seja uma tarefa árdua, pode ser mais produtivo quando focado no processo. Como bem lembra Bazerman (2015):

Escrever é, inevitavelmente, um processo, mesmo que sejam apenas dois minutos para ler um e-mail, reconhecer que precisamos responder, decidir o que precisamos comunicar, escolher as melhores palavras e revisar antes de pressionar o botão "enviar". Não importa que o processo dure dois minutos ou uma década: os impulsos e as palavras iniciais na página podem não estar nem perto do que o documento final será. (BAZERMAN, 2015, p. 188).

Confiar no processo, especialmente nos estágios iniciais da escrita, é muito importante, pois as ideias sobre como o texto final será podem não estar formadas, com pouco sentido concreto. Essa é uma realidade muito pertinente 
à escrita escolar, pois os alunos precisam dessa condução processual para que se efetive o real aprendizado da escrita.

O professor, nesse contexto, deixa de ser um mero corretor de textos e adquire o papel de intérprete, de colaborador, de coautor, de alguém que conhece as dificuldades de seus alunos e atua no sentido de superá-las. Obviamente, isso requer um novo olhar, uma mudança de paradigma pautada em um trabalho gradativo de interlocução e de devoluções da produção escrita em um processo contínuo que passa pelas etapas sugeridas.

Por fim, vale ressaltar que a feitura e a refeitura de um texto é um processo interminável, porque o que acaba mesmo é o tempo para a entrega final da produção textual, mas o caminho percorrido deverá fazer toda a diferença na tomada de consciência do professor, do aluno e de seu texto. 


\section{Referências}

ANTUNES, I. Aula de português: encontro \& interação. São Paulo: Parábola Editorial, 2003.

BARTHES, R. A Retórica Antiga. In COHEN, J.et al. Pesquisas de Retórica. Petrópolis: Vozes, 1975, p. 147-224.

BAZERMAN, C. Retórica da ação letrada. São Paulo: Parábola Editorial, 2015.

CAVAlCANTE, M. M.; CUSTÓDIO FILHO, V.; BRITO, M. A. P. Coerência, referenciação e ensino. São Paulo: Cortez, 2014.

FERREIRA, L. A. Leitura e persuasão: princípios de análise retórica. São Paulo: Contexto, 2015.

GERALDI, J. W. O texto na sala de aula: leitura e produção. Cascavel: Assoeste, 1984.

MACEDO, L. de, ASSIS, Bernadete A. (Orgs.). Psicanálise \& pedagogia. São Paulo: Casa do Psicólogo, 2002

MILLER, C. R. Genre as social action. In: FREEDMAN, A.; MEDWAY, P. (Org.). Genre and the new rhetoric. London: Taylor \& Francis 1994. p. 23-42. Originalmente publicado em: Quarterly Journal of Speech, v. 70, p. 151-167, 1984.

PASSARELLI, L. G. Ensino e correção na produção de textos escolares. São Paulo: Cortez, 2012.

TRINGALI, D. A retórica antiga e outras retóricas: a retórica como crítica literária, São Paulo: MUSA, 2014. 
